\title{
Another Case on Discounted FCF vs. P2S Valuation: Privately Held Food \& Drinks Firms in Greece
}

\author{
Athanasios D. Karampouzis, Dimitrios Ginoglou \\ University of Macedonia, Thessaloniki, Greece
}

\begin{abstract}
This paper is a step-by-step attempt in applying two different valuation methodologies on privately held firms in Greece. Initially the two methodologies—free cash flows to equity and the price-to-sales multiple (P2S)—are being explained. These two models are further developed under the Greek accounting standards (especially the first model, being a more fundamental approach), in order to be applied afterwards more correctly to Greek firms' data, leading to adjusted forms. The application of these two models comes right next upon privately held food \& drinks firms' financial statements, collected for each year (2013 up to 2015). The final step consists of the analysis and discussion of the results with the help of descriptive statistics (frequencies), as well as the pearson statistic, as a simple correlation tool.
\end{abstract}

Keywords: firm valuation, private firm, FCFE, price-to-sales multiple

\section{Introduction}

This part of our work-in-progress in private firm valuation is in fact a methodology on how to appraise SMEs in Greece. After having applied them on the hotel sector and discussing the results (Karampouzis \& Ginoglou, 2017), we chose to further examine application to food and drinks firms, since it is considered as another cut-edge sector of the Greek economy, even whilst being in the middle of a severe recession. We also chose these particular two methodologies (discounted free cash flows to equity and price-to-sales valuation) because much of the private business valuation literature and professionals suggest them (Duke, 2001), for the flexibility and other advantages they offer.

Our motivation to research these two methodologies jointly applied on private firm data relies upon lack on private firm valuation literature in Greece, considering the fact that SMEs are the backbone of the Greek economy. We wish to provide solid examples of how they can be applied and examine the results in contrast. Our final goal is to find any sort of discrepancies on applications of them on SMEs and create applicable models. Of course various other adjustments can be made, when applying these models, such as marketability discounts, accounting adjustments, or even finding more accurate and customized private firm betas, but we consider this study as an intermediate step, towards implementing a more complete modeling of private firm valuation for Greek firms in the future.

Athanasios D. Karampouzis, Ph.D. candidate, University of Macedonia, Thessaloniki, Greece.

Dimitrios Ginoglou, professor, University of Macedonia, Thessaloniki, Greece.

Correspondence concerning this article should be addressed to Athanasios D. Karampouzis, El. Venizelou Str. 22, 54624, Thessaloniki, Greece. 


\section{Literature Review}

\section{The FCFE Discounted Valuation Model}

The first model consists of free cash flows to equity discounted to the present using a discount rate (Stowe, Robinson, Pinto, \& McLeavey, 2007). Free cash flows to equity (FCFE) are calculated using data from the Income Statement and Balance Sheet of the companies under valuation (since there is no obligation for private firms of publishing Cash Flow Statements):

$$
F C F E=N I+N C C-F C I n v-W C I n v+N B
$$

NI stands for Net Income, which can be easily retrieved from the firm's Income Statement, assuming that all revenues and expenses are fully depicted in the Statement. In Greek firms' statements particularly (up to the year 2014, but also many privately held firms chose to continue the former charts of accounts for 2015), this item is retrieved not from the Income Statement, but from another one, known as Table of Income Distribution (Ginoglou, 2014). Net non-Cash Charges are items in the Statement that may decrease earnings, but do not require an outlay of cash. The most common case of such impairment is depreciation expenses of fixed capital. Due to the fact that such charges are not operational outflows, they are added back to net income to depict the real cash flow picture to the investor.

The Investment in Fixed Capital (FCInv) is actually the percentage increase in fixed capital from one financial year to the next that required funding and, of course, is not included as an expense in the Income Statement, but rather as an Asset in the Balance Sheet:

$$
F C I n v=F C_{t}-F C_{t-1}
$$

Investments in Working capital-WCInv—(increases in inventory, accounts receivables etc or decreases in accounts payable, short-term debt etc) may conceal cash or cash equivalent charges and should, therefore, be included as a decreasing item during calculation of FCFF, as well, excluding actual cash items, though (when calculating working capital just for valuation purposes) (Abrams, 2010):

$$
\begin{aligned}
& W C I n v=W C_{t}-W_{t-1}=\left[\left(\text { CurAssets }_{t}-\text { Cash }_{t}\right)-\left(\text { ShortTermL iab }_{t}-\text { NotesPayable }_{t}-\right.\right. \\
& \text { CurPotionL ongTermDebt } \left.\left._{t}\right)\right]-\left[\left(\text { CurAssets }_{t}-\text { Cash }_{t-1}\right)-\left(\text { ShortTermL iab }_{t-1}-\text { Cash }_{t-1}\right)\right. \\
& \text { - CurPotionL ongTermDeb } \left.\left.t_{t-1}\right)\right]
\end{aligned}
$$

Net Borrowing (NB) is net debt less debt repayments for the financial year we study. In fact, it is long term debt plus notes payable and current portion of long term debt, items we excluded during calculation of working capital:

$$
N B=\text { LongTermDe bt }+ \text { NotesPayab le }+ \text { CurPotionL ongTermDeb } t
$$

The discount rate may vary, depending on the specific variation of the discounted model used. We use a one-stage constant growth model (mainly known as Gordon Growth Model), namely a discount rate equal to required rate of return less growth rate (Damodaran, 2001):

$$
V_{t}=\frac{F C F E_{t}}{r-g}
$$


The first issue that comes up under this approach is the fact that we analyze private firms and, thus, there cannot be any market-driven required rate of return. For this reason, we followed another path (Hitchner, 2006): first, we calculated two public food and drinks firms' betas using the CAMP model (Reilly \& Schweihs, 2004). The firms' stocks are being traded in the Athens Stock Exchange (ASE) for many years and as a market index we considered the one of the broader super sector "FTSE ASEFOOD AND DRINKS", because of lack of data of a more specific one (Goulas, Blanas, \& Gomes, 2008). Afterwards we calculated the average beta, using the arithmetic mean and finally, using a risk-free rate (the rate of five-year Greek bonds issued in 2014), which is rather high (4.75\%) because of the notorious recession of the Greek economy and the following financing agreements with the IMF and the European Union, we calculated a rate of return in which we considered that all private firms of our sample will converge (Pratt, 1998).

$$
\begin{gathered}
E\left(R_{J}\right)=R_{F}+\beta_{J}\left[E\left(R_{M}-R_{F}\right)\right] \\
r=\frac{\sum_{j=1}^{2} E\left(R_{j}\right)}{2}
\end{gathered}
$$

The second issue that came up was that we had to assume a growth rate consistent to the numerator, a.k.a. the FCFE. We observed that calculating growth using FCFE would be really volatile, taking in response the volatility of FCFE itself, so we finally made use of a more "smooth" constant g, $g=S_{t} / S_{t-1}-1$ as an average mean of the growths of every year for each company, where for each year we calculated it using annual sales as measure:

$$
g=S_{t} / S_{t-1}-1
$$

Finally, the model for (each year and each company) takes the following form:

$$
V_{a}=V_{i t}=\frac{N I_{i t}+N C C_{i t}-\left(F C_{i t}-F C_{i t-1}\right)-\left(W C_{i t}-W C_{i t-1}\right)+N B_{i t}}{\frac{\sum_{j=1}^{2} E\left(R_{j}\right)}{2}-\left(S_{t} / S_{t-1}-1\right)}
$$

\section{The P2S Multiple Valuation Model}

Price-to-sales is a common multiple used often when valuating private firms (Feldman, 2005) for various reasons: sales are less subjected to accounting distortions than earnings. Moreover, earnings are far more variable than equity values, leading to high volatility when using earnings multiples (Adams \& Thornton, 2009). Sales, on the other hand, are generally less variable, contributing to relatively less volatility in the revenue multiple.

Applying this model, we considered capitalizations of the two public firms (Athens Stock Exchange)—instead of just considering price—and we divided each one for each year $(2013,2014,2015)$ to sales of each, respectively (Fernandez, 2015). Afterwards, we calculate the average price-to-sales ratio for each year: 


$$
\frac{C_{t}}{S_{t}}=\frac{\sum_{j=1}^{2} \frac{C_{j}}{S_{j}}}{2}
$$

Considering that into this average ratio every private firm would converge, we calculate an approximate market capitalization for each private firm using its annual sales:

$$
V_{b}=V_{i t}=\frac{C_{t}}{S_{t}} S_{i t}
$$

\section{Results \& Discussion}

Our sample initially consists of 44 non-public food and drinks firms. The small sample occurred due to the fact that many firms chose not to publish financial data for 2015, reclaiming the right not to, a right that was provided by the recent accounting law. We consider certain classes of value, beginning from negative values in order to cover a lot of cases appraised with the discounted FCFE model. Our final goal, as mentioned above, is to present discrepancies of the two methodologies, when applied jointly.

Table 1

Frequency and Cumulative Frequency for Both Models for the Year 2013

\begin{tabular}{lllll}
\hline Year 2013 & \multicolumn{2}{c}{ Discounted FCFE appraised } & P2S ratio appraised \\
\hline Sets & Frequency & Cumulative $\%$ & Frequency & Cumulative \% \\
\hline$-100,000,000$ & 0 & 0.00 & 0 & 0.00 \\
$-50,000,000$ & 1 & 3.13 & 0 & 0.00 \\
$-20,000,000$ & 1 & 6.25 & 0 & 0.00 \\
0 & 20 & 68.75 & 10 & 22.73 \\
$200,00,000$ & 10 & 100.00 & 21 & 70.45 \\
$50,000,000$ & 0 & 100.00 & 5 & 81.82 \\
$100,000,000$ & 0 & 100.00 & 2 & 86.36 \\
More & 0 & 100.00 & 6 & 100.00 \\
\hline
\end{tabular}

Table 2

Frequency and Cumulative Frequency for Both Models for the Year 2014

\begin{tabular}{lllll}
\hline Year 2014 & \multicolumn{3}{c}{ Discounted FCFE appraised } & P2S ratio appraised \\
\hline Sets & Frequency & Cumulative $\%$ & Frequency & Cumulative \% \\
\hline$-100,000,000$ & 0 & 0.00 & 0 & 0.00 \\
$-50,000,000$ & 2 & 5.88 & 0 & 0.00 \\
$-20,000,000$ & 0 & 5.88 & 0 & 0.00 \\
0 & 16 & 52.94 & 7 & 15.91 \\
$20,000,000$ & 15 & 97.06 & 25 & 72.73 \\
$50,000,000$ & 1 & 100.00 & 5 & 84.09 \\
$100,000,000$ & 0 & 100.00 & 3 & 90.91 \\
More & 0 & 100.00 & 4 & 100.00 \\
\hline
\end{tabular}

As one may observe from the table above only half of the firms present a positive, non-zero value when 
using the FCFF discount model, in contrast to the values using the multiple P2S. This may happen due to the fact that P/S valuation may not produce negative results (as sales will always be at least zero). Thus, it may be important to eliminate rows with negative results (which mostly are zero in P2S valuation terms, but not exclusively), since there may be firms with constant negative results that do not comply with the going-concern hypothesis, which is vital for using the discounted FCFF model. However, since we are talking about privately-held firms it is also essential to be understood that even with negative results, a firm may function for years, since employees, family members, and friends mostly may be underpaid, or even work for free and only one may be compensated, a fact that derives from the family governance management style of SMEs (Bathala, Bowlin, \& Dukes, 2003). So, relying on this possibility, these values are not eliminated.

Table 3

Frequency and Cumulative Frequency for Both Models for the Year 2015

\begin{tabular}{lllll}
\hline Year 2015 & \multicolumn{3}{c}{ Discounted FCFE appraised } & P2S ratio appraised \\
\hline Sets & Frequency & Cumulative $\%$ & Frequency & Cumulative \% \\
\hline$-100,000,000$ & 0 & 0.00 & 0 & 0.00 \\
$-50,000,000$ & 0 & 0.00 & 0 & 0.00 \\
$-20,000,000$ & 1 & 2.70 & 0 & 0.00 \\
0 & 17 & 48.65 & 5 & 11.36 \\
$20,000,000$ & 17 & 94.59 & 24 & 65.91 \\
$50,000,000$ & 1 & 97.30 & 8 & 84.09 \\
$100,000,000$ & 1 & 100.00 & 4 & 93.18 \\
More & 0 & 100.00 & 3 & 100.00 \\
\hline
\end{tabular}

Table 4

Positive, Non-Zero Cumulative Frequency for All Years

\begin{tabular}{lll}
\hline Year & \% DISC value $>0$ & \% P2S value $>0$ \\
\hline 2013 & 31 & 78 \\
2014 & 47 & 84 \\
2015 & 51 & 89 \\
\hline
\end{tabular}

Table 5

Pearson Statistic for All Years

\begin{tabular}{llll}
\hline Year & 2015 & 2014 & 2013 \\
\hline Pearson & 0.236 & -0.230 & -0.359 \\
\hline
\end{tabular}

Similar results we get when we try to observe any correlation, using the Pearson Coefficient. The poor correlation between the values of the two methods enhances our suspicion that negative values distort any potential correlation, namely indicating that both methods produce a right value of the firms.

\section{References}

Abrams, J. B. (2010). Quantitative business valuation. Hoboken, New Jersey: John Wiley \& Sons Inc.

Adams, M., \& Thornton, B. (2009). A comparison of alternative approaches to equity valuation of privately held entrepreurial firms. Journal of Finance and Accountancy, 1(2).

Bathala, C. T., Bowlin, O. D., \& Dukes, W. P. (2003). Corporate governance, illiquidity, and valuation issues in privately-owned corporations. Journal of Entrepreneurial Finance, 8(1), 1-27. 
Damodaran, A. (2001). The dark side of valuation: Valuing old tech, new tech and new economy companies. Upper Saddle River, New Jersey: NV: Financial Times Prentice Hall.

Duke, P. W. (2001). Where do we stand on closely-held firm valuation? The Journal of Entrepreneurial Finance, 6(1), $129-155$.

Feldman, S. J. (2005). Principles of private firm valuation. Hoboken, New Jersey: John Wiley \& Sons Inc.

Fernandez, P. (2015). Valuation using multiples: How do analysts reach their conclusions? Available at SSRN 274972.

Ginoglou, D. (2014). Tax accounting 2. Thessaloniki: Ginoglou D. Publications.

Goulas, A., Blanas, G., \& Gomes, E. (2008). The formation of strategic groups in the Athens stock exchange. MIBES Transactions, 60-77.

Hitchner, J. R. (2006). Financial valuation: Applications and models (2nd ed.). Hoboken, New Jersey: John Wiley \& Sons Inc.

Karampouzis, A. D., \& Ginoglou, D. (2017). Discounted free cash flows vs price-to-sales multiple valuation: A case of appraising privately held hotels in Greece. 24th Annual MFS Conference. Bucharest: MFS.

Pratt, S. P. (1998). Cost of capital: Estimation and applications. USA: John Wiley \& Sons Inc.

Reilly, R. F., \& Schweihs, R. P. (2004). The handbook of business valuation and intellectual property analysis. USA: The McGraw-Hill Companies Inc.

Stowe, J. D., Robinson, T. R., Pinto, J. E., \& McLeavey, D. W. (2007). Equity asset valuation. Hoboken, New Jersey: John Wiley \& Sons Inc. 